\title{
Article
}

\author{
Doi 10.5943/sif/6/1/28
}

\section{Dominance of monoverticillate penicilli in the cold arid soils of Drass valley, India}

\section{Nonzom S and Sumbali G}

\author{
Department of Botany, University of Jammu, B.R. Ambedkar Road, Jammu-180006, India
}

Nonzom S, Sumbali G 2021 - Dominance of monoverticillate penicilli in the cold arid soils of Drass valley, India. Studies in Fungi 6(1), 378-390, Doi 10.5943/sif/6/1/28

\begin{abstract}
During a mycological survey of soil from Drass Valley (3200 msl), more than 40 filamentous fungal isolates belonging to different genera were recovered. Among the recovered isolates, penicilli were found to be the dominant genus and were represented by thirteen species viz., Penicillium adametzi, $P$. bilaiae, $P$. citrinum, $P$. herquei, $P$. implicatum, P. italicum, P. miczynskii, $P$. resedanum, $P$. restrictum, $P$. roseopurpureum, $P$. sclerotiorum, $P$. verrucosum and $P$. vinaceum. Of these, at least 8 Penicillium species were found to be monoverticillate, 3 biverticillate and 2 were terverticillate. Soils of mountains represent environments that prove challenging for the diverse living entities including the microfungi. Since, Drass is the coldest place in India, it is probable that due to extreme and stress conditions that prevail almost throughout the year, these monoverticillate Penicillium species have adapted and evolved over the years as the simplest reproductive structures that can be produced at low metabolic costs.
\end{abstract}

Keywords - Higher prevalence - India - low temperature - Penicillium - Taxonomy

\section{Introduction}

The genus Penicillium represents a group of Class Ascomycetes that occur globally with their diverse species known to be as potent decomposers of organic substrates. Numerous species have been recognized for their ecological and biotechnological prospects, whereas some species have been identified as phytopathogens and are responsible for most of the post-harvest rots affecting the food industry and economy (Frisvad \& Samson 2004, Kim et al. 2007, Pitt \& Hocking 2009, Leitao 2009, Khan et al. 2010, Gawas-Sakhalkar et al. 2012). They have been reported to be one of the most common microfungi inhabiting soil, plants, indoor and outdoor air, different food commodities, etc.

The term "Penicillium" was coined by Link (1809) to describe a group of microfungi that bear brush-like structures, the penicillus with initially three species under this genus, i.e., $P$. candidum, P. expansum and P. glaucum (Houbraken \& Samson 2011). However, later, a large number of species were further added to this genus. Species of Penicillium have been placed under different groups on the basis of the branching of conidiophores, viz., monoverticillate (conidiophore/stipe-unbranched with a terminal cluster of phialides), biverticillate (conidiophore/stipe-branched to form the metulae bearing terminal cluster of phialides), terverticillate (conidiophore/stipe-display second order of branching to form rami and further metulae bearing terminal cluster of phialides) and so on. These different branching patterns help in the morphological identification of Penicillium species. Raper \& Thom (1949) classified the Penicillium species which produced monoverticillate conidiophores into the Monoverticillata group. They also included some species with conidiophores showing irregular branching along with 
the penicilli species with monoverticillate branching. However, later Pitt (1979) based on the conidiophores branching grouped the penicilli species into different sections: a) Section/Subgenus Aspergilloides encompassing penicilli characteristically producing monoverticillate branching and with phialides mostly ampulliform in shape; b) Section/Subgenus Penicillium encompassing penicilli characteristically producing terverticillate condidiophores and some rare quaterverticillate types with mostly ampulliform phialides; c) Section/Subgenus Biverticillium encompassing penicilli characteristically producing biverticillate conidiophores with acerose phialides; d) Section/Subgenus Furcatum encompassing rest of the penicilli producing biverticillate to irregular robust conidiophores with metulae usually of longer and non-uniform length.

Cold arid regions of Himalaya are characterized by a frail ecosystem and a complex climate with considerable heterogeneity owing to the striking seasonal shifts in biochemical and physical properties, thereby imposing rigorous limitations on the activities of a variety of biological forms including microfungi. Ladakh is a high-altitude cold desert and is bordered by the chain of Karakoram Mountains in the north and by the Himalayas in the south (Rawat \& Adhikari 2005). This Karakoram range acts as a barrier for most of the monsoon bearing clouds rendering the region arid. Drass valley (2,800 masl), located in Kargil is also known as the Himalayan gateway to Ladakh and is considered as the coldest place in India and second coldest inhabited place in the world with temperature recorded below $-45^{\circ} \mathrm{C}$ during the winters. In view of the intense environmental conditions, investigations were carried out to assess the diversity and prevalence of cold tolerant microfungi from the soil of this cold desert region.

\section{Materials \& methods}

\section{Sampling and isolation}

Soil samples were collected aseptically from Drass valley by scraping the superficial layer, not exceeding 3-5 cm in depth, with the help of properly sterilized spatula and were brought to the laboratory in pre-sterilised polythene bags. For isolation, dilution pour plate method was adopted using modified Czapek Dox agar (CDA) supplemented with streptomycin sulphate $(50 \mathrm{mg} / 1000$ $\mathrm{ml})$ and Rose Bengal $(0.1 \mathrm{mg} / 100 \mathrm{ml})$. The cultures were deposited in the departmental fungal repository. Facesoffungi numbers were obtained as mentioned by Jayasiri et al. (2015).

\section{Cultural and microscopic observations}

Colony diameter were measured using a measuring scale $(15 \mathrm{~cm})$ in $\mathrm{mm}$ and cultural characteristics, such as, colony texture, colour, exudates, colour of exudates and soluble pigments were observed. Microscopic preparations were made in lactophenol cotton blue (LCB) whereas microscopic line drawings were made with the help of camera lucida at 400x and 1000x magnifications. Dimensions were determined for stipe, metulae, phialides and conidia with the help of an ocular micrometer (Erma, Japan). Microphotography of the fungal cultures was done using Sony N50 camera attached to an Olympus CH 20i binocular microscope. The recovered fungal isolates were identified by studying their cultural and morphological characters. For the purpose of identification, the recovered fungal species were grown and made to sporulate on different culture media, particularly Czapek yeast agar (CYA) and malt extract agar (MEA) media. The recovered species of Penicillium were identified by following the taxonomic key given by Pitt (1979) and other relevant literature.

\section{Percentage colonization frequency $(\mathrm{CF} \%), \mathrm{A} / \mathrm{F}$ ratios and colony forming units $(\mathrm{CFU})$ of the recovered fungal species}

Percentage colonization frequency ( $\mathrm{CF} \%), \mathrm{A} / \mathrm{F}$ ratio, abundance and cfu/g were calculated for each fungal species using formulae given in Table 1.

\section{Results}

Among the various psychrotrophic microfungal species that were recovered from the 
sampled soils, Penicillium was represented by maximum number of species (13) viz., P. adametzi, $P$. bilaiae, $P$. citrinum, $P$. herquei, $P$. implicatum, $P$. italicum, $P$. miczynskii, $P$. resedanum, $P$. restrictum, $P$. roseopurpureum, $P$. sclerotiorum, $P$. verrucosum and $P$. vinaceum (Table 2$)$. These results are in accordance with that of Sonjak et al. (2006) who reported high occurrence and dominance of Penicillium species from three different polythermal Arctic glaciers. Being often psychrotolerant and sturdy, in combination with having the ability to produce abundant number of conidia, penicillia are among the few viable fungi that have been isolated from glacial ice cores (Abyzov 1993). Several similar studies have revealed high frequency of Penicillium species from dry, saline or polar habitats, such as, Arctic and Antarctic soils, permafrost, sea ice, snow and sea water (Vishniac 1993, McRae et al. 1999, Gunde-Cimerman et al. 2003, Ivanushkina et al. 2005, Frisvad et al. 2006). Genus Penicillium encompasses mostly those species, which show tolerance in cold environments as demonstrated by the fact that they can grow on food preserved in refrigerators (Pitt \& Hocking 1999) and have been isolated from alpine, tundra (Domsch et al. 1980) and polar soils (McRae et al. 1999, Frisvad 2004). Recently, the dominance of Penicillium species in glacial ice with diverse bioactive potential has been well documented from Antarctica (De Menezes et al. 2020). In addition to cold tolerance, Dhakar et al. (2014) reported the ability of 25 Penicillium species inhabiting the high-altitude soils of the Indian Himalayan region to tolerate extremes of cold temperature, $\mathrm{pH}$ and salt indicating their adaptive capabilities and flexibilities.

Table 1 Formulae used

\begin{tabular}{l}
$\qquad \mathrm{CF}(\%)=\frac{\text { Number } \text { of soil samples colonized by a specific fungus }}{\text { Total number of samples studied }} \times 100$ \\
W/F ratio = Abundance/Colonization frequency \\
Where: abundance $=\frac{\text { Total number of colonies of a specific fungus }}{\text { Number of soil samples colonized by a specific fungus }}$ \\
A/F ratios describe the distribution pattern of each fungal species into one of the following \\
three categories: \\
A/F ratio of $<0.025$ depicts that the fungal species has regular distribution \\
A/F ratio between $0.025-0.05$ depicts that fungal species has random distribution \\
A/F ratio of $>0.05$ depicts that the fungal species has contagious distribution \\
\hline CFU/g a a d/s \\
Where: a = average number of colonies on the petriplate; $d=$ dilution factor $(10,000), \mathrm{s}=\mathrm{dry}$ \\
weight of the soil sample
\end{tabular}

Out of the diverse species of Penicillium that were recovered during the present investigation, $P$. adametzi, $P$. herquei $P$. implicatum, $P$. italicum, $P$. restrictum, and $P$. roseopurpureum and $P$. vinaceum have been reported from hot arid and semi-arid soils (Grishkan et al. 2003, Oliveira et al. 2013). Representatives of cold habitats are exemplified by penicilli, such as, $P$. citrinum, $P$. implicatum and $P$. miczynskii, $P$. restrictum and $P$. verrucosum, which have been reported from permafrost sediments of Arctic and Antarctic regions (Ivanushkina et al. 2005, Kochkina et al. 2012). However, there are no reports on the occurrence of $P$. bilaiae, $P$. resedanum and $P$. sclerotiorum from the hot or cold desert soils and thus constitute new additions to the existing list of desert mycoflora.

Perusal of data presented in Table 2 shows that Penicillium adametzi, $P$. roseopurpureum and $P$. sclerotiorum have regular distribution with $\mathrm{A} / \mathrm{F}$ ratios $<0.0250$. On the other hand, $P$. citrinum, $P$. herquei, $P$. italicum, $P$. miczynskii, $P$. resendanum, $P$. restrictum, and $P$. vinaceum were 
randomly distributed whereas rest of the species were contageously distributed with $\mathrm{A} / \mathrm{F}$ ratios > 0.05 .

During the present investigation, most of the Penicillium species recovered from the soil of Drass valley were observed to have monoverticillate penicilli in contrast to the bi or ter-verticillate Penicillium species (Table 2). Many mycological studies from the cold regions of the globe have shown the occurrence of monoverticillate penicilli along with the Penicillium species with other branching types (Godinho et al. 2013, Dhakar et al. 2014, Pandey et al. 2016, De Menezes et al. 2020). Data also shows that most of these monoverticillate penicilli displayed maximum percentage colonization frequency $(\mathrm{CF} \%)$ with $P$. vinaceum $(60)$ closely followed by $P$. adametzi (56) and $P$. roseopurpureum (56). Similarly, highest colony forming units (cfu) were recorded for $P$. vinaceum $\left(3.1 \times 10^{3}\right)$, whereas least were that for $P$. implicatum and $P$. italicum $\left(0.5 \times 10^{3}\right)$ each (Table 2).

Table 2 Penicillium species recovered from the soil samples of Drass valley

\begin{tabular}{|c|c|c|c|c|c|c|}
\hline \multirow[b]{2}{*}{$\begin{array}{l}\text { Penicillium species } \\
\text { recovered }\end{array}$} & \multirow[b]{2}{*}{ Type of penicilli } & \multicolumn{5}{|c|}{ Number of soil samples analysed $=25$} \\
\hline & & $\begin{array}{l}\text { Number of } \\
\text { samples } \\
\text { detected } \\
\text { positive }\end{array}$ & $\begin{array}{l}\text { CF } \\
(\%)\end{array}$ & Abundance & $\mathrm{A} / \mathrm{F}$ ratio & cfu/g \\
\hline $\begin{array}{l}\text { Penicillium } \\
\text { adametzi }\end{array}$ & Monoverticillate & 14 & 56 & 1.14 & 0.020 & $1.6 \times 10^{3}$ \\
\hline P. bilaiae & Monoverticillate & 4 & 16 & 1.50 & 0.093 & $0.6 \times 10^{3}$ \\
\hline P. citrinum & Monoverticillate & 8 & 32 & 1.50 & 0.046 & $1.2 \times 10^{3}$ \\
\hline P. herquei & Biverticillate & 12 & 48 & 1.91 & 0.039 & $2.3 \times 10^{3}$ \\
\hline P. implicatum & Monoverticillate & 3 & 12 & 1.66 & 0.138 & $0.5 \times 10^{3}$ \\
\hline P. italicum & Terverticillate & 5 & 20 & 1.00 & 0.050 & $0.5 \times 10^{3}$ \\
\hline P. miczynskii & Biverticillate & 7 & 28 & 1.14 & 0.040 & $0.8 \times 10^{3}$ \\
\hline P. restrictum & Monoverticillate & 9 & 36 & 1.55 & 0.043 & $1.4 \times 10^{3}$ \\
\hline P. resendanum & Monoverticillate & 8 & 32 & 1.37 & 0.042 & $1.1 \times 10^{3}$ \\
\hline P. sclerotiorum & Monoverticillate & 12 & 48 & 1.16 & 0.024 & $1.4 \times 10^{3}$ \\
\hline$P$. roseopurpureum & Monoverticillate & 14 & 56 & 1.14 & 0.020 & $1.6 \times 10^{3}$ \\
\hline P. vinaceum & Monoverticillate & 15 & 60 & 2.06 & 0.034 & $3.1 \times 10^{3}$ \\
\hline P. verrucosum & Terverticillate & 3 & 12 & 2.00 & 0.166 & $0.6 \times 10^{3}$ \\
\hline
\end{tabular}

Taxonomy

\section{Penicillium roseopurpureum Dierckx}

Facesoffungi Number: FoF 10492

\section{Culture characteristics}

Colonies on CYA 15-20 mm in diameter, radially sulcate to convolute, centrally raised, deep and dense with surface texture velutinous; margins deep, mycelium white; conidiogenesis pale grey; exudates present, blood red (Fig. 1b, shown in arrow); soluble pigment brown to red orange; reverse deep brown.

Colonies on MEA 15-22 mm in diameter, plane, moderately deep; mycelium white, surface texture velutinous to markedly funiculose; margins low and wide; conidiogenesis light to moderate, dull green; exudates and soluble pigment absent; reverse pale.

\section{Microscopic characteristics}

Conidiophores borne from aerial hyphae, stipes short, 11.2-15.4 $\mu \mathrm{m}$, smooth-walled, strictly monoverticillate, nonvesiculate or slightly swollen (Fig. 1); phialides in verticils 3-6, measuring 4.9-6.3 × 1.4-1.5 $\mu \mathrm{m}$; ampulliform, with short collula; conidia spheroidal, measuring 1.4-2.0 $\mu \mathrm{m}$, with walls finely roughened, borne in short and well-defined columns (Fig. 1a, c). 
Distinctive features: slow growth; production of red pigmentation, non-vesiculate stipe with spheroidal and roughened conidia.

\section{Penicillium sclerotiorum Beyma}

Facesoffungi Number: FoF 10493

\section{Culture characteristics}

Colonies on CYA $30-35 \mathrm{~mm}$ in diameter after 5 days of incubation, annularly sulcate, centrally convolute, low to moderately deep, dense, consisting of a layer of mycelium, white at the margins, followed by a yellow buff mycelium and commonly grey green nearer the colony centres, overlaid by scattered penicilli, in sectors or zonate (Fig. 1e, shown in arrow), conidiogenesis sparse, greenish grey; orange red exudates present; brown soluble pigment usually produced; reverse sectored or unevenly pigmented.

Colonies on MEA $32-35 \mathrm{~mm}$ in diameter, plane, centrally convolute, low and dense to somewhat floccose; conidiogenesis sparse to moderate, in colours similar to those produced on CYA; exudates and soluble pigment absent; reverse in shades similar to those on CYA.

\section{Microscopic characteristics}

Conidiophores borne from surface or subsurface hyphae, stipes long and slender, smooth to finely roughened; strictly monoverticillate, vesiculate, $14-56 \times 1.4-1.5 \mu \mathrm{m}$; phialides numerous, upto 4-9 per verticil, ampulliform, 4.3-6.7 $\times 1.4-2.1 \mu \mathrm{m}$ with long collula; conidia $1.5-2.0 \mu \mathrm{m}$ in diameter (Fig. 1d, f).

Distinctive features: colonies zonate, prominent orange red exudates.

\section{Penicillium vinaceum Gilman \& Abbott}

Facesoffungi Number: FoF 10494

\section{Culture characteristics}

Colonies on CYA 12-15 $\mathrm{mm}$ in diameter after 7 days of incubation, dense to floccose, radially sulcate, margin deep; mycelium white at the margins, buff in the centre; conidiogenesis moderate, grey green; exudate yellow; pigmentation red (Fig. 1j, shown in arrow), reverse yellowish brown.

Colonies on MEA $15-18 \mathrm{~mm}$ in diameter after 7 days of incubation at $28 \pm 2^{\circ} \mathrm{C}$, dense, convex, margin low, narrow; mycelium white at the margins and buff elsewhere. Conidiogenesis moderate, dull green, reverse yellow.

\section{Microscopic characteristics}

Conidiophores borne from single hyphae, stipes short, 12.6-30.8 $\times 1.6-2.8 \mu \mathrm{m}$, smoothwalled, strictly monoverticillate, nonvesiculate (Fig. 1g-h). Phialides in verticils of 4-7, ampulliform, 5.6-7.0 $\times 1.4-2.1 \mu \mathrm{m}$. Conidia spheroidal, smooth, measuring 1.5-2.5 $\mu \mathrm{m}$, with obvious disjunctors between the conidia, borne in short disordered chains (Fig. 1g-h, shown in arrows)

Distinctive features: vinaceous exudates on CYA, short conidiophores, strictly monoverticillate and non-vesiculate stipe.

\section{Penicillium adametzii Zaleski}

Facesoffungi Number: FoF 10541

\section{Culture characteristics}

Colonies on CYA 33-35 mm in diameter after 7 days at $28 \pm 2^{\circ} \mathrm{C}$, moderately deep, lightly sulcate or convolute, conspicuously funiculose; margins low, entire; mycelium white; 
conidiogenesis light, dull green; pale yellow exudates sometimes present; soluble pigment absent; reverse pale.

Colonies on MEA $25-30 \mathrm{~mm}$ in diameter, after 7 days at $28 \pm 22^{\circ} \mathrm{C}$ plane, very deep, conspicuously funiculose; margins low; entire; mycelium white; conidiogenesis light; coloured as on CYA; exudates and soluble pigment absent; reverse pale.

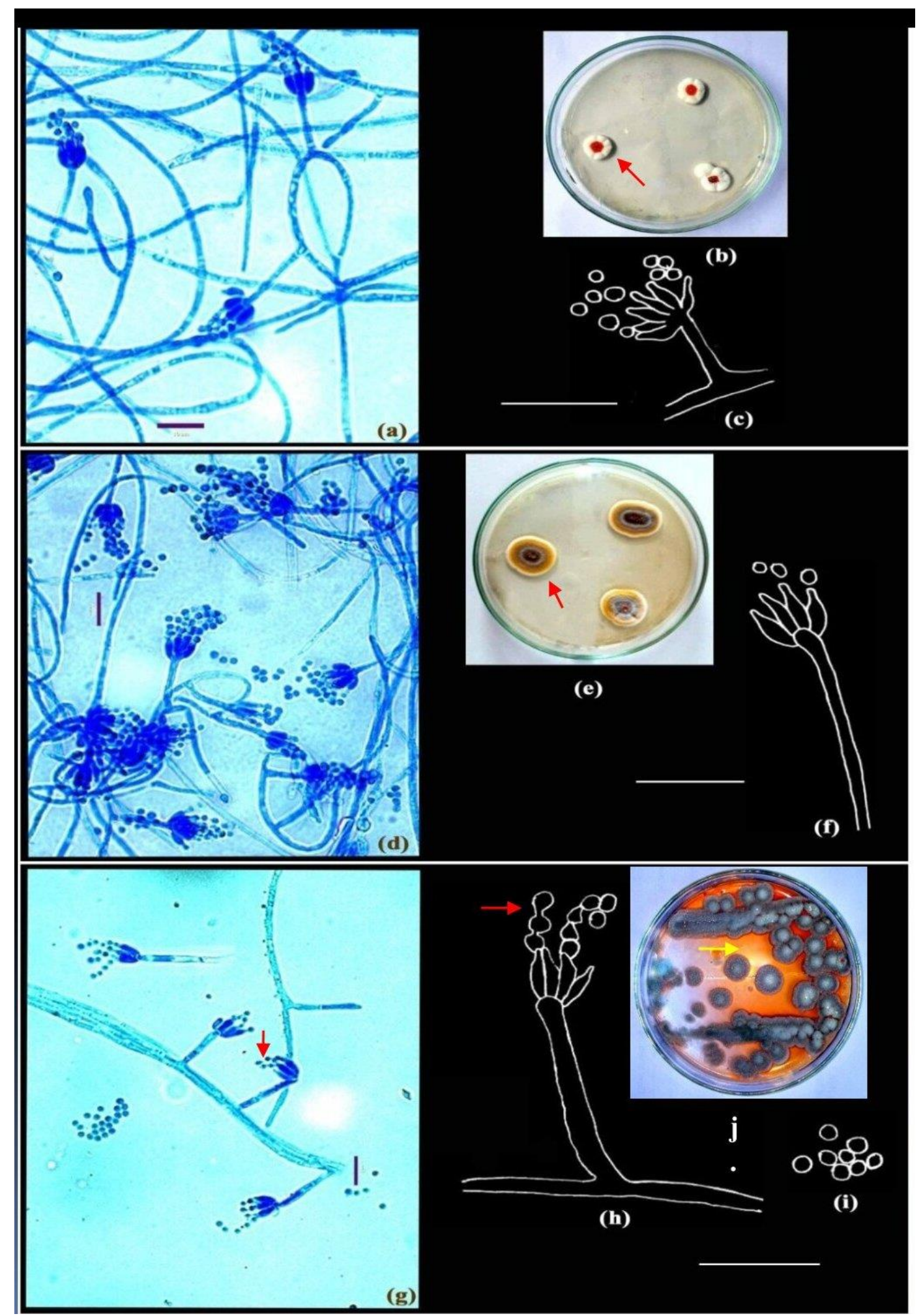

Fig. 1 - a-c Penicillium roseopurpureum Dierckx. d-f Penicillium sclerotiorum Beyma. g-j Penicillium vinaceum Gilman \& Abbott. Colonies growing on CYA (b, e, j); Microphotographs (a, d, g); Camera lucida drawings (c, f, h-i). Scale bars: a, d, g =10 $\mu \mathrm{m}, \mathrm{c}, \mathrm{f}, \mathrm{h}-\mathrm{i}=14 \mu \mathrm{m}$. 


\section{Microscopic characteristics}

Conidiophores borne principally from funicles and single aerial or surface hyphae; stipes short, measuring 11.2-56.0 $\mu \mathrm{m}$ in length, with smooth walls, strictly monoverticillate, nonvesiculate; phialides in compact verticils of 3-6, ampulliform, 4.2-7.5 × 1.4-2.1 $\mu \mathrm{m}$; with long, slender collula; conidia spheroidal, $1.5-2.5 \mu \mathrm{m}$ in diameter, smooth to finely roughened, borne in short columns, ellipsoidal, measuring 2.1-2.8 $\mu \mathrm{m}$, borne in long chains (Fig. $2 \mathrm{a}-\mathrm{c}$ ).

Distinctive features: conidiophores short, borne at right angles from the trailing hyphae, conidia finely roughened.

\section{Penicillium bilaiae Chalabuda}

Facesoffungi Number: FoF 10542

\section{Culture characteristics}

Colonies on CYA $20-25 \mathrm{~mm}$ in diameter, after 7 days of incubation at $28 \pm 2^{\circ} \mathrm{C}$, plane, consisting of moderately floccose to funiculose white mycelium; margins wide, conidiogenesis light to moderate, dull green; clear exudates present; soluble pigment absent; reverse pale.

Colonies on MEA $20-25 \mathrm{~mm}$ in diameter, after 7 days of incubation at $28 \pm 2^{\circ} \mathrm{C}$, plane, mycelium white, surface texture velutinous to markedly funiculose; margins low and wide; conidiogenesis light to moderate, dull green; exudates and soluble pigment absent; reverse pale.

\section{Microscopic characteristics}

Conidiophores borne from aerial hyphae, either solitary or in funicles, stipes smooth-walled, straight, strictly monoverticillate, terminally spathulate or vesiculate up to $4.2 \mu \mathrm{m}$ diameter (Fig. $2 \mathrm{e}$, shown in arrow); phialides crowded, parallel, in verticils of upto 11 , ampulliform, measuring 7.0-8.0 $\times 1.4-1.5 \mu \mathrm{m}$, with short collula; conidia spheroidal, measuring $2.1 \mu \mathrm{m}$ in diameter, with rugulose walls, borne in well-defined columns (Fig. 2d-f).

Distinctive features: broad vesiculate conidiophores.

\section{Penicillium implicatum Biourge}

Facesoffungi Number: FoF 10543

\section{Culture characteristics}

Colonies on CYA slow growing, $15-20 \mathrm{~mm}$ diameter after 7 days of incubation at $28 \pm 2^{\circ} \mathrm{C}$, radially sulcate and centrally umbonate. Mycelium dense, white; conidiogenesis heavy, greyish green; exudate absent; reverse brown.

On MEA colonies slow growing, reaching 14-19 $\mathrm{mm}$ diameter in 7 days, colour and morphology similar to culture on CYA; exudate and soluble pigments absent.

\section{Microscopic characteristics}

Conidiophores borne from surface hyphae; stipes 60-88 $\mu \mathrm{m}$ long, with smooth and thin walls, monoverticillate, vesiculate, 3.0-4.2 $\mu \mathrm{m}$ wide (Fig. $2 \mathrm{~g}-\mathrm{h}$, shown in arrows); phialides in verticils of 6-8, typically ampulliform with short collula, 7.0-9.8 $\times 1.5-2.6 \mu \mathrm{m}$. Conidia spheroidal, smooth, borne in loose columns, measuring 2.5-2.8 $\mu \mathrm{m}$ in diameter (Fig. $2 \mathrm{~g}-\mathrm{i}$ ).

Distinctive features: slow growing colonies, vesiculate conidiophores.

\section{Penicillium resedanum McLennan \& Ducker}

Facesoffungi Number: FoF 10544

\section{Culture characteristics}

Colonies on CYA $10-15 \mathrm{~mm}$ in 5 days at $28 \pm 2{ }^{\circ} \mathrm{C}$, plane, compact, deep, floccose; margins entire, deep; mycelium white at the margins, elsewhere very brightly coloured, yellowish green 
(Fig. 3a1, shown in arrow); conidiogenesis light, dull green; clear exudates present; soluble pigment absent; reverse bright orange.

Colonies on MEA 15-20 mm in diameter, plane, centrally umbonate, relatively sparse, floccose; margins fimbriate; mycelium brightly coloured, greenish yellow; conidiogenesis light; exudates and soluble pigment absent; reverse dull orange brown.

\section{Microscopic characteristics}

Conidiophores borne from aerial hyphae, stipes with smooth walls, strictly non-vesiculate, bearing terminal and sometimes subterminal verticils of phialides (Fig. 3e, shown in arrow); phialides in divergent verticils of 3-8, acerose, measuring 7.0-14 $\times 1.4-2.1 \mu \mathrm{m}$; with long gradually tapering collula; conidia ellipsoidal, smooth-walled, 2.1-2.8 $\mu \mathrm{m}$ in size, borne in disordered chains (Fig. 3a-d).

Distinctive features: slow growing colonies with light conidiogenesis with green yellow mycelium, acerose phialides.

\section{Penicillium restrictum Gilman and Abbott}

Facesoffungi Number: FoF 10545

\section{Culture characteristics}

Colonies on CYA $15-20 \mathrm{~mm}$ in diameter, plane to slightly radially sulcate, deep and floccose; mycelium white; conidiogenesis sparse, greenish-grey, minute exudate present; reverse pale cream.

On MEA colonies slow growing, 15-18 $\mathrm{mm}$ in diameter, umbonate; mycelium white, margin greenish white; conidiogenesis moderate, conidia in mass greenish grey, minute droplets of clear exudate present; reverse pale.

\section{Microscopic characteristics}

Conidiophores borne from loose aerial hyphae; stipes characteristically short, 14.0-35.2 $\times$ 1.5-2.5 $\mu \mathrm{m}$, smooth-walled. Penicilli strictly monoverticillate, nonvesiculate (Fig. 3 e-f); phialides 3-5 per verticil, 4.2-8.4 × 1.4-2.5 $\mu \mathrm{m}$. Conidia spheroidal, $2.1-2.8 \mu \mathrm{m}$ in diameter, echinulate, at maturity with prominent disjunctors, borne in short irregular chains (Fig. 3g).

Distinctive features: relatively slow growing colonies, short stipes and phialides, rough conidia.

\section{Penicillium citrinum Thom}

Facesoffungi Number: FoF 10546

\section{Culture characteristics}

Colonies on CYA 23-25 mm in diameter, radially sulcate, marginal area velutinous, margins low; mycelium white in periphery and white to greyish orange at the centre. Conidiogenesis moderate to heavy; exudates clear, pale yellow, copious over the central half of the colony; reverse olive brown.

Colonies on MEA 13-15 mm in diameter, plane, radially slightly sulcate, dense; mycelium white to greyish orange, margins narrow and typically irregular. Conidiogenesis heavy, grey blue to dull green; reverse pale yellow.

\section{Microscopic characteristics}

Stipes smooth, characteristically terminating in well-defined verticils of 3-5 divergent metulae, which are of uniform length, measuring 11.2-12.6 $\times 2.1-2.8 \mu \mathrm{m}$, slightly vesiculate. Phialides 3-7 per verticil, ampulliform, 7.0-8.4 × 1.4-2.8 $\mu \mathrm{m}$ with short collula. Conidia smooth, spheroidal, 2.1-2.8 $\mu \mathrm{m}$, typically borne in long well defined columns (Fig. 4a-b). 


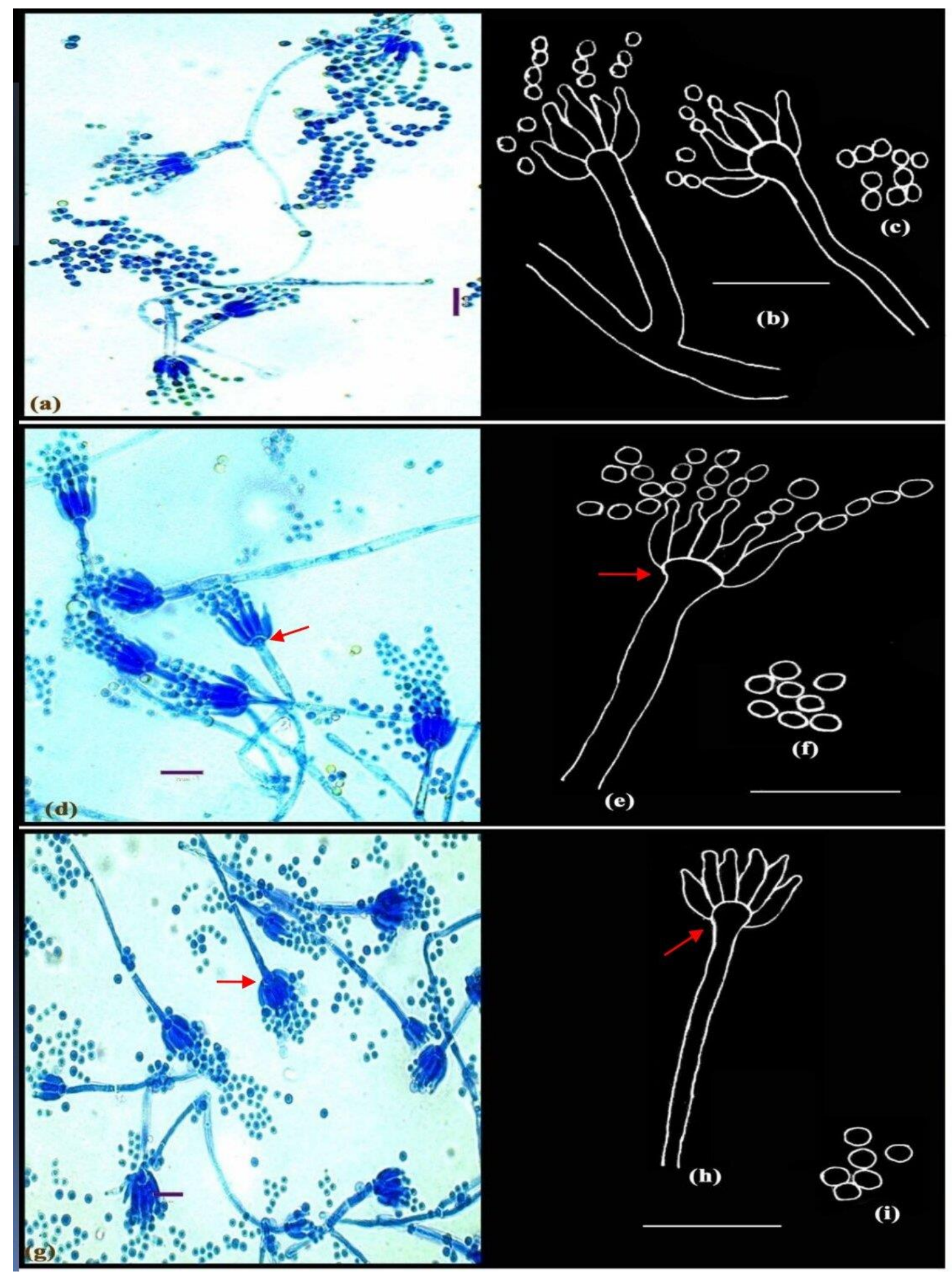

Fig. 2 - a-c Penicillium adametzii Zaleski. d-f Penicillium bilaiae Chalabuda. g-i Penicillium implicatum McLennan \& Ducker; Microphotographs ( $\mathrm{a}, \mathrm{d}, \mathrm{g}$ ); Camera lucida drawings (b-c, e-f, h-i). Scale bars: a, d, g =10 $\mu \mathrm{m}, \mathrm{b}-\mathrm{c}, \mathrm{e}-\mathrm{f}, \mathrm{h}-\mathrm{i}=14 \mu \mathrm{m}$.

\section{Penicillium miczynskii Zaleski}

Facesoffungi Number: FoF 10547

\section{Culture characteristics}

Colonies on CYA $20-25 \mathrm{~mm}$ in diameter, radially sulcate, velutinous, deep and floccose; margins entire, narrow; mycelium pastel yellow; conidiogenesis sparse, dull green; pale yellow exudate and pigment present; reverse orange yellow. 
Colonies on MEA 18-22 mm in diameter, plane, centrally umbonate, low, sparse and velutinous; margins deep, entire; mycelium as on CYA; reverse yellow green.

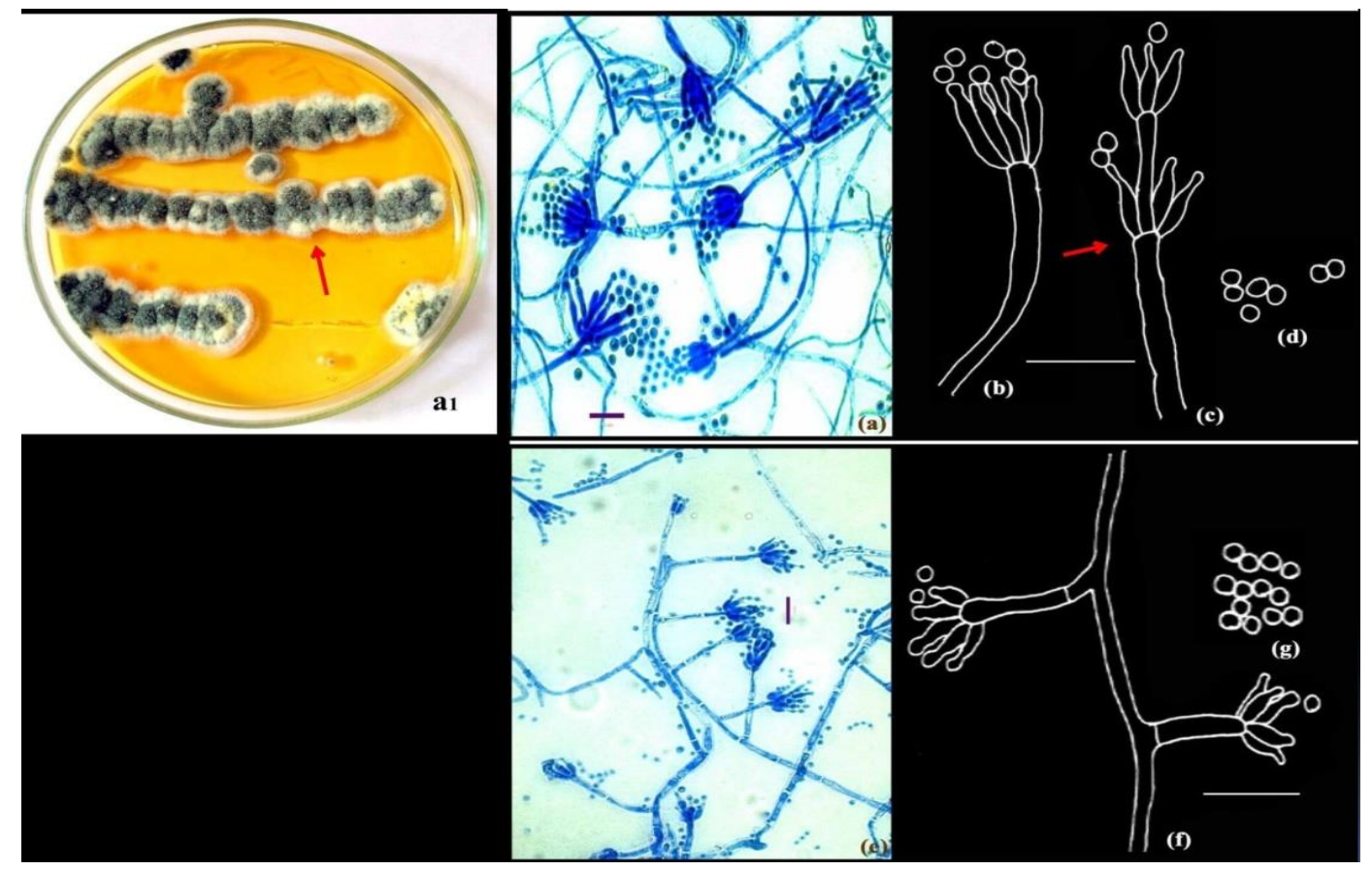

Fig. 3 - a1-d Penicillium resedanum McLennan \& Ducker. Colonies growing on CYA (a1). e-f Penicillium restrictum Gilman and Abbott.); Microphotographs (a, e); Camera lucida drawings (b-d, f-g). Scale bars: a, e = 10 $\mu \mathrm{m}, \mathrm{b}-\mathrm{d}, \mathrm{f}-\mathrm{g}=14 \mu \mathrm{m}$.

\section{Microscopic characteristics}

Conidiophores borne singly from subsurface hyphae, stipes long and delicate with thin, smooth walls, bearing biverticillate or less commonly non-vesiculate monoverticillate penicilli; metulae characteristically in well-defined verticils of 3-5, measuring 7-13 $\times 1.4-2.8 \mu \mathrm{m}$; phialides in compact verticils, 5-8 per metula, ampulliform, measuring 5.5-7.0 × 1.8-2.0 $\mu \mathrm{m}$; conidia subspheroidal, measuring 2.0-2.8 $\mu \mathrm{m}$, rough-walled (Fig. 4c-d).

Distinctive features: yellow pigment in the mycelium, penicilli biverticillate with long delicate stipes.

\section{Penicillium italicum Wehmer}

Facesoffungi Number: FoF 10548

\section{Culture characteristics}

Colonies on CYA 15-20 mm in diameter, plane, moderately deep, dense, margins entire; mycelium white, conidiogenesis heavy, dull bluish green; clear exudates present in small amounts; reverse pale.

Colonies on MEA 16-24 $\mathrm{mm}$ in diameter, plane and sparse, surface texture slightly velutinous; conidiogenesis moderate; exudates and soluble pigment absent; reverse pale green.

\section{Microscopic characters}

Conidiophores borne from subsurface hyphae, stipes smooth, bearing large regular to irregular terminal terverticillate penicilli; rami $1-2$ per penicillus, measuring $14.4-22.4 \times 1.6-3.2$ $\mu \mathrm{m}$; metulae in verticils of 2-4, measuring 9.2-18.2 $\times 2.5-4.2 \mu \mathrm{m}$, apically inflated; phialides 2-5 per metula, measuring 7.7-14 × 2.1-4.06 $\mu \mathrm{m}$. Conidia borne as cylinders from the collula, enlarging and rounding with maturation, spherical to subglobose, with smooth walls, measuring 2.9-4.6 $\times 4.2 \mu \mathrm{m}$, borne in long disordered chains (Fig. 4e-f). 


\section{Penicillium herquei Bainer \& Sartory}

Facesoffungi Number: FoF 10549

\section{Culture characteristics}

Colonies on CYA 11-20 mm, radially sulcate, dense, flocose, margins deep; mycelium light yellow; conidiogenesis moderate, brilliant green; orange to yellow exudates present; soluble pigment typically produced, greenish yellow; reverse pale.

Colonies on MEA 15-22 mm diameter, plane, dense, floccose; margins deep, mycelium yellow, centrally green; conidiogenesis moderate, light green; exudates and soluble pigment absent; reverse deep olive.

\section{Microscopic characteristics}

Conidiophores borne from aerial mycelium; stipes smooth-walled, long, typically bearing terminal verticils of 3-6, closely appressed metulae, measuring 7.0-11.2 $\times 1.4-2.1 \mu \mathrm{m}$; phialides in verticils of 3-6, ampulliform, measuring 7.7-11.2 $\times 1.8-2.1 \mu \mathrm{m}$, with short abruptly tapering collula; conidia ellipsoidal, obovoid, measuring $2.8-4.2 \times 2.8 \mu \mathrm{m}$, with walls conspicuously roughened, borne in disordered chains (Fig. $4 \mathrm{~g}-\mathrm{h}$ ).

Distinctive features: compact penicilli with a terminal cluster of appressed metulae, ellipsoidal to obovate rough conidia.

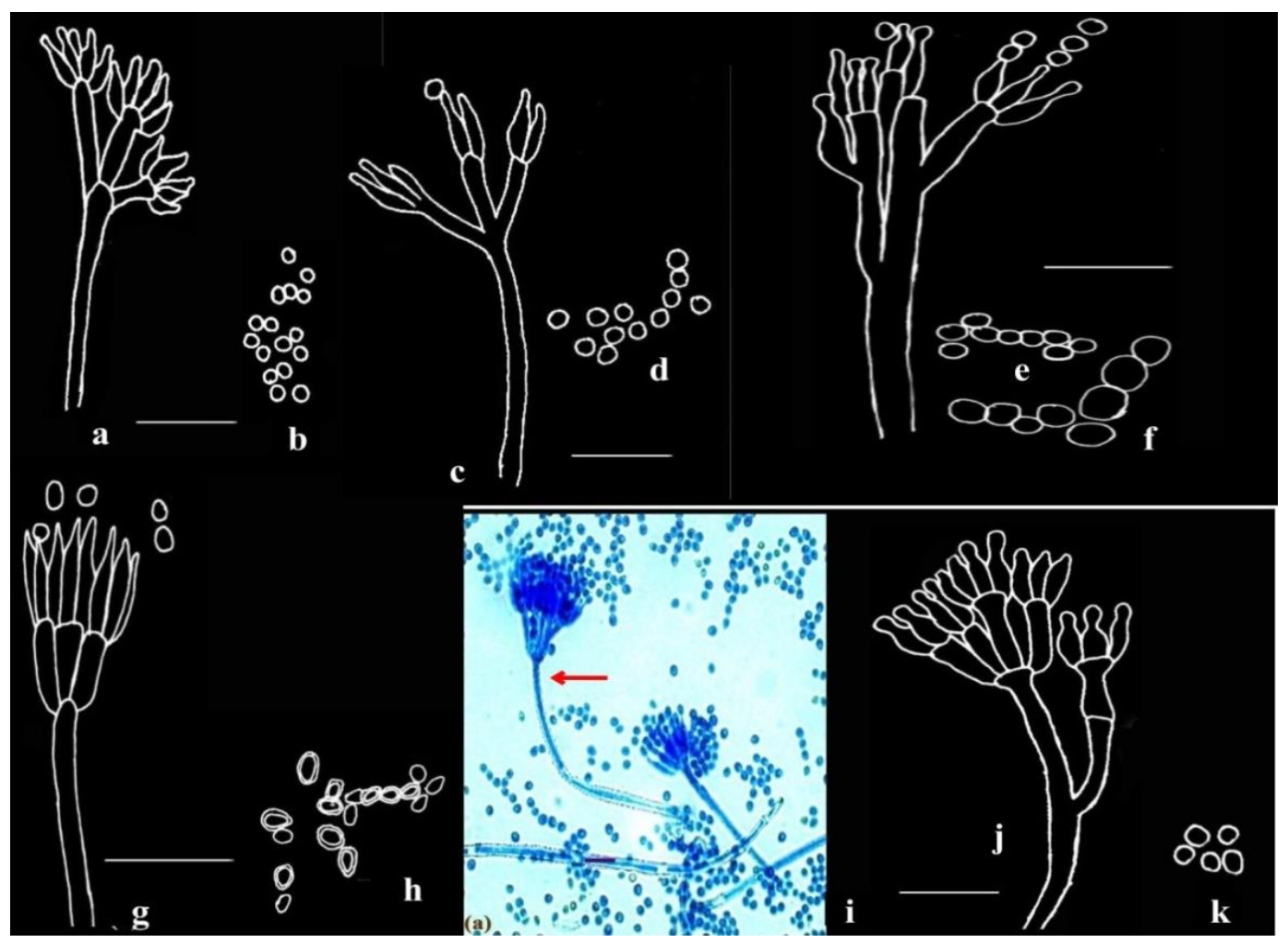

Fig. 4 - a-b Penicillium citrinum Thom. c-d Penicillium miczynskii Zaleski. e-f Penicillium italicum Wehmer. g-h Penicillium herquei Bainer \& Sartory. I-k Penicillium verrucosum Dierckx; Microphotograph (i); Camera lucida drawings (a-h, j-k). Scale bars: $\mathrm{a}-\mathrm{h}, \mathrm{j}-\mathrm{k}=14 \mu \mathrm{m}, \mathrm{i}=10 \mu \mathrm{m}$.

\section{Penicillium verrucosum Dierckx}

Facesoffungi Number: FoF 10550

\section{Culture characteristics}

Colonies on CYA 15-20 mm in diameter, radially sulcate, velutinous; margins low, narrow; mycelium white; conidiogenesis light to moderate, dull green; pale yellow exudate typically 
produced; soluble pigment absent, reverse yellow brown.

Colonies on MEA 10-15 mm in diameter, radially sulcate, centrally umbonate, dense and velutinous; margins low; mycelium white; conidiogenesis moderate, dull green; exudates absent; reverse dull brown.

\section{Microscopic characteristics}

Conidiophores borne singly from subsurface hyphae, stipes typically long and robust with walls finely roughened (shown in arrow), bearing terminal terverticillate and quaterverticillate penicilli; metulae in verticils of 3-5, measuring 9.8-15.4 × 2.5-2.9 $\mu \mathrm{m}$; phialides $2-5$ per metula, ampulliform, measuring 7.0-9.8 $\times 2.1-2.5 \mu \mathrm{m}$, narrowing abruptly to short collula; conidia spherical, measuring 2.5-2.8 $\mu \mathrm{m}$, smooth-walled (Fig. 4i-k).

\section{Conclusion}

Ladakh region represents an unexplored region in India in terms of microbiological studies. It caught the attention of researchers in the recent years with the discovery of many novel microbes from similar habitats. In the present study we observed the dominance of Penicillium taxa which are known to withstand cold temperatures. Drass valley, being the coldest place in the Himalayan region, the microbes apparently remain less active and dormant for most part of the year and since penicilli have been considered as one of the cold tolerant fungi, their probability of incidence from such extreme environments augments with decrease in temperature to zero to sub-zero temperatures. Through this study it is felt that these monoverticillate microfungal species have adapted and evolved over the years with their high frequency and dominance which could be attributed to their diverse survival capabilities and strategies. Preferential formation of simplest reproductive structures that can be produced at low metabolic costs could be one such strategy.

\section{Acknowledgements}

The first author is grateful to University Grants Commission (UGC), New Delhi for the financial assistance in the form of Rajiv Gandhi National Fellowship (RGNF), which facilitated the study. The authors are also thankful to UGC SAP DRS-II for providing lab facilities.

\section{References}

Abyzov SS. 1993 - Microorganisms in the Antarctic ice. In: Friedman EI (eds), Antarctic Microbiology. Wiley-Liss Inc, New York pp. 265-285.

De Menezes GCA, Porto BA, Amorim SS. 2020 - Fungi in glacial ice of Antarctica: diversity, distribution and bioprospecting of bioactive compounds. Extremophiles 24, 367-376.

Dhakar K, Sharma A, Pandey A. 2014 - Cold, pH and salt tolerant Penicillium spp. inhabit the high-altitude soils in Himalaya, India. World Journal of Microbiology and Biotechnology 30, 1315-1324.

Domsch KH, Gams W, Anderson TH. 1980 - Compendium of soil fungi. Academic Press, London, pp. 1-859.

Frisvad JC, Larsen TO, Dalsgaard PW. 2006 - Four psychrotolerant species with high chemical diversity consistently producing cycloaspeptide A, Penicillium jamesonlandense sp. nov., Penicillium ribium sp. nov., Penicillium soppii and Penicillium lanosum. International Journal of Systematic and Evolutionary Microbiology 56, 1427-1437.

Frisvad JC. 2004 - Chemical diversity of psychrotolerant fungi. In: Watanabe MM, Suzuki K and Seki T (eds), Innovative Roles of Biological Resources Centers. Japan Society for Culture Collections and Worlds Federation of Culture Collections, Tsukuba, pp. 165-167

Frisvad J, Samson RA. 2004 - Polyphasic taxonomy of Penicillium subgenus Penicillium. A guide to identifcation of food and airborne terverticillate Penicillia and their mycotoxins. Studies in Mycology 49, 1-173. 
Gawas-Sakhalkar P, Singh SM, Simantini N, Ravindra R. 2012 - High-temperature optima phosphatases from the cold-tolerant Arctic fungus Penicillium citrinum. Polar Research 31.

Godinho VM, Furbino LE, Santiago IF, Pellizzari FM et al. 2013 - Diversity and bioprospecting of fungal communities associated with endemic and cold-adapted macroalgae in Antarctica. ISME Journal 7, 1434-1451.

Grishkan I, Nevo E, Wasser SP. 2003 - Soil micromycete diversity in the hypersaline Dead Sea costal area, Israel. Mycological Progress 2, 19-28.

Gunde-Cimerman N, Sonjak S, Zalar P, Frisvad JC et al. 2003 - Extremophilic fungi in Arctic ice: a relationship between adaptation to low temperature and water activity. Physics and Chemistry of Earth 28, 1273-1278.

Houbraken J, Samson RA. 2011 - Phylogeny of Penicillium and the segregation of Trichocomaceae into three families. Studies in Mycology 70, 1-51.

Ivanushkina NE, Kochkina GA, Ozerskaya SM. 2005 - Fungi in ancient permafrost sediments of the Arctic and Antarctic regions. In: Castello J, Rogers S (eds), Life in ancient ice. Princeton Press, Princeton, NJ, pp. 127-140.

Jayasiri SC, Hyde KD, Ariyawansa HA, Bhat J et al. 2015 - The Faces of Fungi database: fungal names linked with morphology, phylogeny and human impacts. Fungal Diversity 74, 3-18 Doi 10.1007/s13225-015-0351-8

Kim WK, Sang HK, Woo SK, Park MS et al. 2007 - Six species of Penicillium associate with blue mold of grape. Mycobiology 35(4), 180-185.

Khan MS, Zaidi A, Ahemad M, Oves M, Wani PA. 2010 - Plant growth promotion by phosphate solubilizing fungi - current perspective. Archieves of Agronomy and Soil Science 56(1), 73 98.

Kochkina G, Ivanushkina N, Ozerskaya S, Chigineva N et al. 2012 - Ancient fungi in Antarctic permafrost environments. FEMS Microbiology Ecology 82, 501-509.

Leitao AL. 2009 - Potential of Penicillium species in the bioremediation field. International Journal of Environ Research and Public Health 6, 1393-1417.

Link HF. 1809 - Observationes in ordinesplantarum naturals. Dissertatio 1 ma. Magazin der Gasellschaft Naturforschenden Freunde Berlin 3, 3-42.

McRae CF, Hocking AD, Seppelt RD. 1999 - Penicillium species from terrestrial habitats in the Windmill Islands, East Antarctica, including a new species, Penicillium antarcticum. Polar Biology 21, 97-111.

Oliveira LG, Cavalcanti MAQ, Fernandes MJS, Lima DMM. 2013 - Diversity of filamentous fungi isolated from the soil in the semiarid area, Pernambuco, Brazil. Journal of Arid Environments 95, 49-54.

Pandey N, Dhakar K, Jain R, Pandey A. 2016 - Temperature dependent lipase production from coldand $\mathrm{pH}$ tolerant species of Penicillium. Mycosphere (special issue).

Doi 10.5943/mycosphere/si/3b/5

Pitt JI. 1979 - The genus Penicillium and its teleomorphic states Eupenicillium and Talaromyces. Academic Press, London, 1-634.

Pitt JI, Hocking AD. 1999 - Fungi and Food Spoilage 2nd ed. Aspen publisher, Inc, Maryland.

Pitt JI, Hocking AD. 2009 - Fungi and Food Spoilage. Springer, New York.

Raper KB, Thom C. 1949 - Manual of the Penicillia. Williams \& Wilkins, Baltimore.

Rawat GS, Adhikari BS. 2005 - Floristics and distribution of plant communities across moisture and topographic gradients in Tso Kar basin, Changthang plateau, eastern Ladakh. Arctic, Antarctic and Alpine Research 37, 539-544.

Sonjak S, Frisvad JC, Gunde-Cimerman N. 2006 - Penicillium mycobiota in Arctic subglacial ice. Microbiol Ecology 52, 207-216.

Vishniac HS. 1993 - The microbiology of Antarctic soils. In: Friedmann EI (eds), "Antarctic Microbiology." Wiley-Liss Inc, New York, USA, pp. 297-342. 